\title{
Oxygen costs using a reciprocating gait orthosis in a paraplegic (T9) patient with a bilateral below-knee amputation: Case report
}

\author{
WDF Smith ${ }^{2}$, PF Clark ${ }^{1}$, D MacArthur ${ }^{1}$, RD Allatt ${ }^{1}, \mathrm{KC} \mathrm{Hayes}^{1}$ and DA Cunningham ${ }^{1}$ \\ ${ }^{1}$ Parkwood Hospital, 801 Commissioners Road East, London, Ontario, N6C 5J1, the ${ }^{2}$ Centre for Activity and Ageing \\ and Department of Physical Medicine and Rehabilitation, University of Western Ontario, London, Ontario, N6A $3 K 7$, \\ Canada
}

\begin{abstract}
The Reciprocating Gait Orthosis (RGO) is a useful aid to ambulation for patients with paraplegia. Its use has been described previously though not in conjunction with limb prostheses. We report here the energy costs of ambulation of a patient, disabled by paraplegia at T9 and bilateral below-knee amputations, walking at her preferred rate using an RGO while gas exchange was measured by the Douglas bag method. Oxygen uptake $\left(\mathrm{VO}_{2}\right)$ rose from $0.1981 \mathrm{~min}^{-1}$ at rest to $0.5821 \mathrm{~min}^{-1}$ in the last minute of exercise, representing a $\mathrm{VO}_{2}$ of $14.73 \mathrm{ml} \mathrm{kg} \mathrm{min}^{-1}$. During the fourth minute of amubulation, energy consumption was $30.44 \mathrm{~J} \mathrm{~kg}^{-1} \mathrm{~s}^{-1}$ with an energy cost of $4.17 \mathrm{~J} \mathrm{~kg}^{-1} \mathrm{~m}^{-1}$ at a velocity of $0.13 \mathrm{~m} \mathrm{~s}^{-1}$. Ambulation with this combination of disability is possible with the aid of limb prostheses and an RGO though it is slow and the energy expenditure as consumption per second and cost per metre are high.
\end{abstract}

Keywords: paraplegia; $\dot{\mathrm{VO}}_{2}$; energy costs; reciprocating gait orthosis (RGO); bilateral belowknee amputation

\section{Introduction}

The ideal goal for any paraplegic person is to be able to walk independently in a manner which is efficient, practical and as near normal as can be achieved. With incomplete lesions, or lesions at a low level, this is frequently possible and practical with the use of aids though the energy costs rise considerably when the lesions are complete and at a thoracic level or higher. The energy costs of ambulation with a Reciprocating Gait Orthosis (RGO) have been described previously in paraplegic patients ${ }^{1}$ though to our knowledge not in relation to an individual also disabled by bilateral below-knee amputations.

The patient, aged 55 years, had been involved in a farm accident three years previously in which she had suffered a complete Frankel class A paraplegia at midthoracic level (T9) requiring fusion of T8-11. She also sustained a flail chest injury which was treated operatively and from which she recovered; there are no subsequent chest complaints. Her lower limbs had been so severely injured as to require bilateral belowknee amputation but on recovery she had learned to ambulate with the aid of limb protheses, an RGO and a folding Rollator (C-483). The purpose of this assessment was to determine the aerobic cost of ambulation with the RGO and limb protheses.

Correspondence: Dr WDF Smith R.D., M.D., M.R.C.P., Consultant Physician, Adult and Elderly Medicine, Countess of Chester Hospital, Chester, CH2 1UL, UK

\section{Methods}

Testing was conducted at the Centre for Activity and Ageing, University of Western Ontario, London, Ontario. At the time of study she was well and taking no prescription medication. On arrival at the laboratory, the patient fitted her limb prostheses and RGO, was weighed and then rested prior to exercise testing. The procedure for the measurement of oxygen uptake $\left(\dot{\mathrm{VO}}_{2}\right)$ and carbon dioxide production $\left(\dot{\mathrm{V}} \mathrm{CO}_{2}\right)$ by the Douglas bag method was then explained.

At rest she was fitted with the breathing apparatus and nose clips, and breathed quietly until she had settled. The patient walked, with her walking aid, down a 40 metre corridor at her preferred rate for $4 \mathrm{~min}$. Expired gas was collected in $60 \mathrm{~s}$ aliquots, beginning in the last minute of rest and for 4 min of exercise. The apparatus was leak-free, had a low inspiratory resistance and was suspended vertically during gas collection to facilitate filling. Heart rate was recorded by a commercially available monitoring device (Sport-tester); the position of the leading foot at the end of each minute provided distance measures to calculate velocity. Following a $30 \mathrm{~min}$ rest period the exercise test and aerobic measurements were repeated.

Expired gas was analyzed to give $\mathrm{O}_{2}$ and $\mathrm{CO}_{2}$ concentrations $(\%)$ by mass spectrometer (AirSpec MGA 2200) which had been calibrated with precision analyzed gas. Minute ventilation ( $\dot{\mathrm{V} e}$ ) was measured at ATPS by Tissot spirometer and corrected to $1 \mathrm{~min}^{-1}$ STPD. Oxygen uptake $\left(\dot{\mathrm{VO}}_{2}\right)$ in the last minute of 
exercise was calculated using the Haldane transformation (formula 1) since expired volumes were measured; inspired volumes for calculation, therefore, were acquired indirectly. Carbon dioxide $\left(\mathrm{VXO}_{2}\right)$ production was calculated using formula 2. Energy expenditure, reported as Kilo-calories per minute $\left(\mathrm{Kcal} \mathrm{min}^{-1}\right)$, was calculated using formula $3^{3}$ with the mean $\dot{\mathrm{VO}}_{2}$ for the last minute of exercise, and energy expenditure as Joules per minute $\left(\mathrm{J} \mathrm{min}^{-1}\right)$ was also calculated using formula $4^{4}$, from which energy consumption $\left(\mathrm{J} \mathrm{kg}^{-1} \mathrm{~s}^{-1}\right)$ and energy costs $\left(\mathrm{J} \mathrm{kg}^{-1} \mathrm{~m}^{-1}\right)$ were calculated. Mean values for the duplicate tests are reported.

\section{Formulae}

$1 \quad \dot{\mathrm{V}} \mathrm{O}_{2}=\dot{\mathrm{Ve}}\left[\left(\% \mathrm{~N}_{2 \exp } * 0.265\right)-\% \mathrm{O}_{2 \exp }\right]$

$2 \quad \dot{\mathrm{V} C O}=\dot{\mathrm{Ve}}\left(\% \mathrm{CO}_{2 \exp }-0.03 \%\right)$

$3 \mathrm{Kcal} \mathrm{min}^{-1}=\dot{\mathrm{V}} \mathrm{O}_{2}$ (1) $* 4.825$

4 Joule $\min ^{-1}=$ Kcal min $^{-1} * 4184.0$

$\left[\% \mathrm{O}_{2 \exp }, \% \mathrm{CO}_{2 \exp }\right.$ and $\% \mathrm{~N}_{2 \exp }=$ expired concentrations $(\%)$ of oxygen, carbon dioxide and nitrogen respectively.]

\section{Results}

The patient weighed $39.5 \mathrm{~kg}$; the RGO and protheses weighed a further $7.5 \mathrm{~kg}$. From a resting $\dot{\mathrm{VO}}_{2}$ of $0.1981 \mathrm{~min}^{-1}$ with a respiratory exchange ratio (RER) of $0.85, \dot{\mathrm{VO}} 2$ increased to $0.5821 \mathrm{~min}^{-1}$ and the RER to 0.97 . Figure 1 shows a plateau in oxygen uptake by $4 \mathrm{~min}$ and the re-establishment of resting $\mathrm{VO}_{2}$ prior to retesting. Additional gas data, including RER and minute ventilation, are tabulated in Table 1 . The

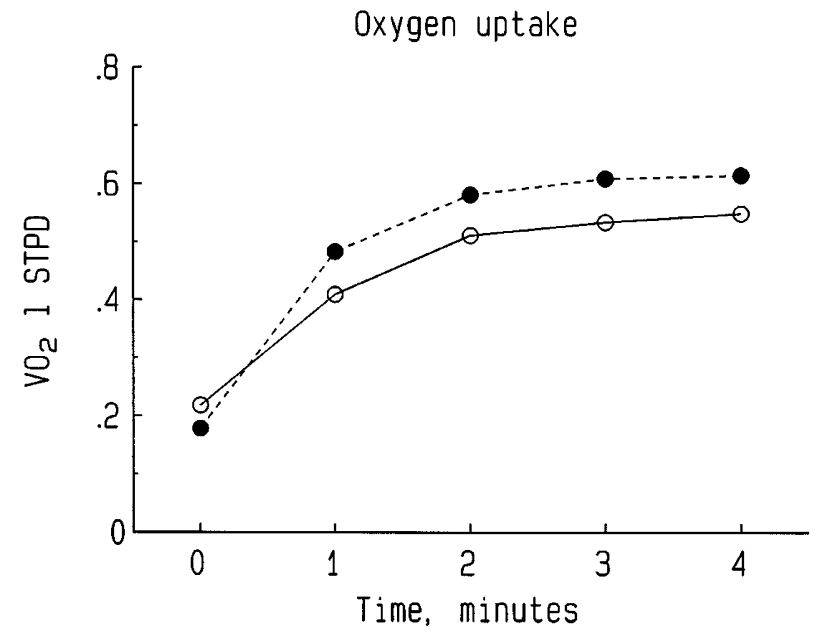

Figure 1 Test 1: Open circles. Test 2: Closed circles

Table 1 Gas exchange data during the fourth minute of exercise

\begin{tabular}{|c|c|c|c|c|c|}
\hline & $\begin{array}{l}\dot{\mathrm{VO}_{2}} \\
\mathrm{~min}^{-1}\end{array}$ & $\begin{array}{c}\mathrm{VO}_{2} \\
\mathrm{ml} \mathrm{kg} \\
\mathrm{min}^{-9}\end{array}$ & $\begin{array}{l}\mathrm{VCO}_{2} \\
l \mathrm{~min}^{-1}\end{array}$ & $R E R$ & $\begin{array}{c}\dot{\dot{V e}} \\
l \mathrm{~min}^{-1} \\
S T P D\end{array}$ \\
\hline Test 1 & 0.549 & 13.9 & 0.566 & 1.03 & 20.66 \\
\hline Test 2 & 0.615 & 15.6 & 0.562 & 0.91 & 21.50 \\
\hline Mean & 0.582 & 14.73 & 0.564 & 0.97 & 21.08 \\
\hline
\end{tabular}

$\dot{\mathrm{VO}}_{2}$, uptake of oxygen per minute; $\dot{\mathrm{VO}}_{2}$, carbon dioxide production per minute. RER, respiratory exchange ratio $\left(\dot{\mathrm{V} C O} \mathrm{O}_{2} \div \dot{\mathrm{V}} \mathrm{O}_{2}\right)$; $\dot{\mathrm{Ve}}$, minute ventilation; STPD, standard temperature and pressure, dry; body mass $39.5 \mathrm{~kg}$

Table 2 Energy expense of ambulation by spinal cord injury patients with orthoses

\begin{tabular}{|c|c|c|c|c|c|}
\hline & $\mathrm{n}$ & $\begin{array}{l}\text { Energy comsump' } \\
\quad J \mathrm{~kg}^{-1} \mathrm{~s}^{-1}\end{array}$ & $\begin{array}{cl}\text { Energy } & \text { Cost } \\
J \mathrm{~kg}^{-1} & \mathrm{~m}^{-1}\end{array}$ & $\begin{array}{l}\text { Velocity } \\
m \mathrm{~s}^{-I}\end{array}$ & $\begin{array}{l}\text { Level } \\
\text { and Aid }\end{array}$ \\
\hline Clinkingbeard (1964) & 2 & 2.22 & 40.80 & 0.05 & T4 KAFO \\
\hline Huang (1979) & 1 & 3.60 & 18.16 & 0.18 & T4 KAFO \\
\hline Chantraine (1984) & 3 & 5.54 & 14.74 & 0.38 & T10-11 KAFO \\
\hline Merkel (1985) & 8 & 4.67 & 15.98 & 0.29 & C7-T12 Braces \\
\hline Merkel (1985) & 8 & 6.21 & 24.31 & 0.26 & C7-T12 KAFO \\
\hline Waters (1985) & 20 & 5.48 & 17.77 & 0.48 & Not spec KAFO \\
\hline Nene (1989) & 10 & 3.10 & 16.0 & 0.21 & T4-T9 Para \\
\hline \multirow[t]{2}{*}{ Nene (1990) } & 5 & 2.59 & 11.22 & 0.23 & T4-7 Para \\
\hline & 5 & 2.50 & 10.56 & 0.24 & T4-7 Para \& ES \\
\hline \multirow{2}{*}{ Edwards (1990) } & 1 & 4.30 & 15.38 & 0.28 & T8 RGO \\
\hline & 1 & 5.47 & 20.27 & 0.27 & T8 RGO+FNS \\
\hline Mean & (77) & 4.21 & 18.41 & 0.32 & \\
\hline Range & & $(2.5-6.2$ & $10.6-31.3$ & $0.13-0.48)$ & \\
\hline This report & 1 & 4.17 & 30.44 & 0.13 & $\mathrm{~T} 6 \mathrm{RGO}+\mathrm{LP}$ \\
\hline
\end{tabular}

Values are individual study means and bracketed values the between study range for the means. Given the varied measurement techniques used in these studies, the diverse orthoses and the subject-specific pathology these data should be interpreted as estimates only for discussion purposes. $\mathrm{KAFO}=$ Knee-ankle-foot orthosis; $\mathrm{ES}=$ Electrical stimulation; $\mathrm{FNS}=$ Functional neuromuscular stimulation; Para $=$ Parawalker; $\mathrm{RGO}=$ Reciprocating gait orthosis; $\mathrm{LP}=$ Limb prostheses 
corresponding heart rates were 75 at rest and 143 in the final minute of exercise. Oxygen costs and velocity are tabulated in Table 2 with data from previously published assessments. ${ }^{5-11}$

\section{Discussion}

Pathological gait is usually less energy efficient than normal gait and, in addition, has a lower average velocity and slower pace frequency. The least embarrassment to normal gait economics can be expected with distal lesions or using devices requiring minimal weight bearing by the upper limbs. ${ }^{12}$ In paraplegia, the burden increases as the level of the lesion rises, leaving the knee unstable and requiring greater leg raise with gait. At a higher level the hip becomes unstable and loses anti-gravity musculature and, as the level rises higher, fewer and fewer functional muscle groups are able to contribute to either limb movement or posture control. Braced lower limbs, though paralysed, may still be functionally superior to the bio-engineered limb prostheses currently available due to imperfections in attachment, articulation and function.

In the present study the patient exhibited very high energy costs consistent with a compass gait characterised by abrupt acceleration and deceleration and forced vertical excursion of the centre of gravity with resultant inefficiencies and excessive energy costs. ${ }^{13}$ Considering the neurological implications alone, this patient falls into that group of patients in whom ambulation may be possible with an RGO but in whom it is seldom practical for any length of time due to the very high energy burdens per unit time (energy consumption) and per unit distance (energy cost). In the steady state her energy costs were approximately nine times those of a normal individual walking at a self-determined pace. ${ }^{14}$

This patient exercised at her preferred rate which was a high but undetermined percentage of maximum. This would have involved both aerobic and anaerobic metabolism though the former would have predominated, as suggested by her RER which approached 1.0. For comparison, a measure of $\dot{\mathrm{VO}}_{2} \max$ and RER at maximum by hand-cranking would have been useful to gauge her ambulatory costs, however, for technical reasons this was not successful and could not be repeated.

Table 2 presents a sample of energy expenditures of ambulation by spinal cord injured patients with orthoses for comparison with the present study. As can be seen, the energy cost described here and the velocity achieved is similar to two of Nene's subjects ${ }^{10}$ with paraplegic levels of T4 and T7, as one might expect, and the velocity achieved was similarly low. These data fall into the high portion of the hyperbolic distribution of Nene's cost-velocity plot.

This patient is no longer able to ambulate with the RGO, largely due to weight gain of $18.5 \mathrm{~kg}$ to $58 \mathrm{~kg}$ which, making no allowances for additional agerelated loss of aerobic capacity, has effectively reduced her peak measured $\dot{\mathrm{VO}}_{2}$ from $14.7 \mathrm{ml}$ $\mathrm{kg}^{-1} \min ^{-1}$ to $8.9 \mathrm{ml} \mathrm{kg}^{-1} \min ^{-1}$ and made her energy costs prohibitive. Instead, she uses a standup chair for many of her activities around her home.

In conclusion, the energy economics of RGO ambulation in spinal cord injured patients are very high compared to normal gait. Nevertheless ambulation, though slow and energetically expensive, is possible in the face of combined neurological and skeletal disability.

\section{References}

1 Edwards BG, Marsolais EB. Energy costs of ambulation with reciprocal gait orthosis, electrical stimulation, long leg braces and hybrids: a case study. Clinical Kinesiology 1990; 44: 43-47.

2 McArdle WD, Katch FI, Katch VL. Exercise Physiology, Lea \& Febiger, 2nd edition, 1986, pp 637-641.

3 Geigy Scientific Tables. Volume 1, 8th edition, Ciba-Geigy, 1981, pp $229-231$.

4 Astrand PO, Rodahl K. Textbook of work physiology; physiological bases of exercise. McGraw-Hill, 3rd edition, 1986.

5 Clinkingbeard JR, Gesten JW, Hoehen D. Energy cost of ambulation in traumatic paraplegia. American Journal of Physical Medicine 1964; 43: $157-165$.

6 Haung CT et al. Energy cost of ambulation in paraplegic patients using Craig Scott braces. Archives of Physical Medicine 1979; 60: $595-600$.

7 Chaintraine A et al. Energy expenditure of ambulation in paraplegics; effects of long term use of braces. Paraplegia 1984; 22: $173-181$.

8 Merkel KD et al. Energy expenditure of paraplegic patients standing and walking with two knee-ankle-foot orthoses. Archives of Physical Medicine and Rehabilitation 1984; 65: $121-124$.

9 Waters RL, Lunsford BR. Energy cost of paraplegia locomotion. Journal of Bone and Joint Surgery (Am) 1985; 67A: 19-26.

10 Nene AV, Patrick JH. Energy cost of paraplegic locomotion with the ORLAU parawalker. Paraplegia 1989; 27: 5-18.

11 Nene AV, Patrick JH. Energy cost of paraplegic locomotion using the parawalker-electrical stimulation hybrid orthosis. Archives of Physical Medicine Rehabilitation 1990; 71: 116-120.

12 Deathe AB. Canes, crutches, walkers and wheelchairs: A review of metabolic energy expenditure. Canadian Journal of Rehabilitation 1992; 5(4): $217-230$.

13 Saunders JB, Inman VT, Eberhart HD. The major determinants in normal and pathological gait. Journal of Bone and Joint Surgery 1953; 35(A): $543-558$.

14 Blessey R. Energy cost of normal walking. Orthopeadic Clinics of North America 1978; 9: 356 - 358. 